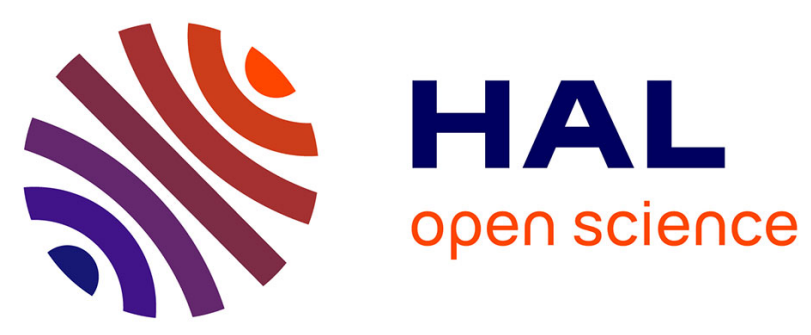

\title{
Synthesis of both enantiomers of \\ ferrocene[1,2-c]1H-quinolin-2-one by diastereoselective deproto-zincation of sugar-derived ferrocene esters
}

Aare Sreeshailam, Gandrath Dayaker, D. Venkata Ramana, Floris Chevallier, Thierry Roisnel, Shinsuke Komagawa, Ryo Takita, Masanobu Uchiyama, Palakodety Radha Krishna, Florence Mongin

\section{To cite this version:}

Aare Sreeshailam, Gandrath Dayaker, D. Venkata Ramana, Floris Chevallier, Thierry Roisnel, et al.. Synthesis of both enantiomers of ferrocene[1,2-c]1H-quinolin-2-one by diastereoselective deproto-zincation of sugar-derived ferrocene esters. RSC Advances, 2012, 2, pp.7030-7032. 10.1039/c2ra21045b . hal-01053780

\section{HAL Id: hal-01053780}

https://hal-univ-rennes1.archives-ouvertes.fr/hal-01053780

Submitted on 1 Aug 2014

HAL is a multi-disciplinary open access archive for the deposit and dissemination of scientific research documents, whether they are published or not. The documents may come from teaching and research institutions in France or abroad, or from public or private research centers.
L'archive ouverte pluridisciplinaire HAL, est destinée au dépôt et à la diffusion de documents scientifiques de niveau recherche, publiés ou non, émanant des établissements d'enseignement et de recherche français ou étrangers, des laboratoires publics ou privés. 


\title{
Synthesis of both enantiomers of ferrocene[1,2-c]1H-quinolin-2-one by diastereoselective deproto-zincation of sugar-derived ferrocene esters
}

\author{
Aare Sreeshailam, ${ }^{a, b}$ Gandrath Dayaker, ${ }^{a, b}$ D. Venkata Ramana, ${ }^{a, b}$ Floris Chevallier, ${ }^{a}$ Thierry Roisnel, ${ }^{c}$ \\ Shinsuke Komagawa, ${ }^{d, e}$ Ryo Takita, ${ }^{d, e}$ Masanobu Uchiyama, ${ }^{d, e}$ Palakodety Radha Krishna ${ }^{* b}$ and \\ ${ }_{5}$ Florence Mongin* ${ }^{a}$
}

\author{
Received (in $X X X, X X X)$ Xth $X X X X X X X X X 20 X X$, Accepted Xth XXXXXXXXX 20XX \\ DOI: 10.1039/b000000x
}

Diastereoselective deproto-metallation of several sugarderived ferrocene esters using lithium-zinc bases was studied. ${ }_{10}$ While bis[(R)-1-phenylethyl]amino as ligand afforded the diacetone-D-glucose-based $\left(S_{\mathrm{P}}\right)$-2-iodoferrocene ester in $91 \%$ de after iodination, the $R_{\mathrm{P}}$ was synthesized from $\alpha$-Dglucofuranose using 2,2,6,6-tetramethylpiperidino as ligand. Both $\left(R_{\mathrm{P}}\right)$ - and $\left(S_{\mathrm{P}}\right)$-ferrocene[1,2-c]1H-quinolin-2-one were 15 reached by subsequent cyclizing coupling, albeit their racemization was noted.

Metallocenes have been intensively studied due to their varied applications in fields such as catalysis, materials science, ${ }^{1}$ and bioorganometallic chemistry. ${ }^{2}$ Amongst all, planar-chiral 20 ferrocenes have attracted the attention of chemists, in particular because of their use in homogeneous asymmetric catalysis. ${ }^{3}$

The presence of a heteroatom-containing substituent on ferrocenes usually directs lithiation onto the adjacent position. With the aim of obtaining enantio-enriched planar-chiral 25 derivatives, reactions of ferrocenes bearing various chiral directing groups have been documented. ${ }^{3 \mathrm{~b}, \mathrm{c}} \mathrm{We}$ have recently contributed to these studies by identifying sugar-derived esters as suitable groups to induce ferrocene diastereoselective deprotometallations using function-compatible lithium-cadmium base $30(\mathrm{TMP})_{3} \mathrm{CdLi}$ (TMP = 2,2,6,6-tetramethylpiperidino) followed by iodination. ${ }^{4}$ Herein, the use of lithium-zinc combinations as nontoxic basic alternatives to achieve chemo- and still diastereoselective syntheses of 2-iodoferrocene esters is described. In order to access targets such as ferrocene[1,2-c]1H35 quinolinones $\mathbf{1}$ from the latter, coupling-cyclization one-pot sequences are next considered (Scheme 1).

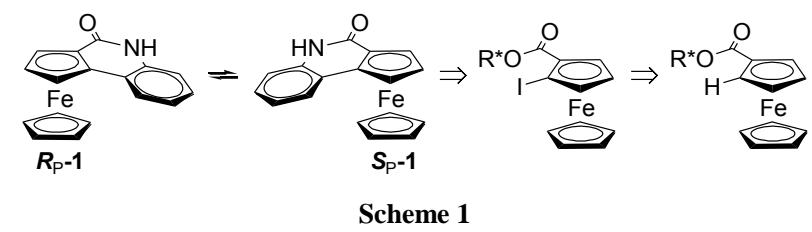

We thus turned our attention to a variety of chiral ferrocene 40 esters, prepared from ferrocenecarboxylic acid and the corresponding secondary alcohols $\mathbf{2 a - g}$ depicted in Scheme 2 under classical conditions. ${ }^{5}$ The metallation reactions were attempted in THF (tetrahydrofuran) at room temperature for 2 hours before interception with iodine (Table 1).

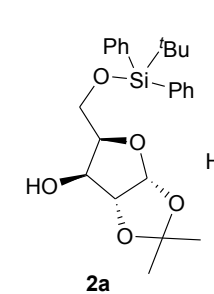

$2 a$

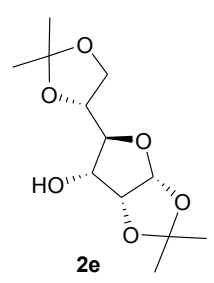

2b

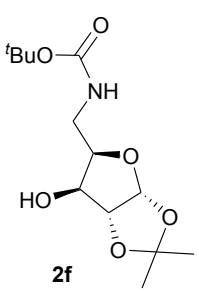

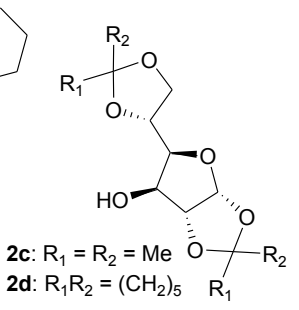

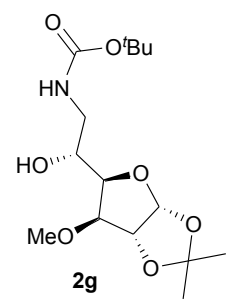

Scheme 2 Chiral alcohols used to prepare the ferrocene esters.

From the $\alpha$-D-xylofuranose derivative $\mathbf{3 a}$, using the lithiumzinc base prepared in situ from $\mathrm{ZnCl}_{2}$.TMEDA (1 equiv, TMEDA $=N, N, N^{\prime}, N^{\prime}$-tetramethylethylenediamine) and TMPLi $50(3 \text { equiv })^{6}$ afforded $\mathbf{4 a}$ in $86 \%$ yield but with a moderate $20 \%$ de. Subsequent reduction to 2-iodoferrocenemethanol (5) using DIBAL- $\mathrm{H}^{7}$ analysis by HPLC using a chiral stationary phase, and comparison with the literature showed the predominant formation of $\mathbf{4 a}$ as $R_{\mathrm{P}}$ diastereomer (Table 1, entry 1). When the ${ }_{55} \alpha$-D-mannofuranose derivative $\mathbf{3 b}$ was treated similarly, the metallation proved incomplete, affording $\mathbf{4 b}$ in $50 \%$ yield and a low $17 \%$ de in favor of the $S_{\mathrm{P}}$ diastereomer (Table 1, entry 2). Under the conditions used to functionalise $\mathbf{3 a}, \mathbf{b}$, the iodo derivatives $\mathbf{4 c , d}$ were synthesized from the inexpensive $\alpha$-D${ }_{60}$ glucofuranose derivatives $\mathbf{3 c , d}$ in $86-87 \%$ yield and $54-56 \%$ de (major $S_{\mathrm{P}}$ diastereomer, Table 1, entries 3,4). Involving the $\alpha$-Dallofuranose derivative $\mathbf{3 e}$ in the reaction, a good conversion was observed but with a disappointing $32 \%$ de in favor of the $S_{\mathrm{P}}$ diastereomer (Table 1, entry 5). In order to evaluate more metal65 coordinating groups, the $\alpha$-D-xylofuranose derivative $3 \mathbf{f f}$ was tested using 1.5 equiv of base, giving $\mathbf{4 f}$ in $70 \%$ yield and a low de (Table 1 , entry 6). With the $\alpha$-D-glucofuranose derivative $\mathbf{3 g}$, both diastereomers were separated and the major one, isolated in $35 \%$ yield, proved to be the $R_{\mathrm{P}}$ (Table 1 , entry 7 ). 
Table 1 Metallation of the chiral ferrocenecarboxylates 3a-g using the lithium-zinc base prepared from $\mathrm{ZnCl}_{2}$. TMEDA (1 equiv) and TMPLi (3 equiv) before trapping with $\mathrm{I}_{2}$ ( 3 equiv).

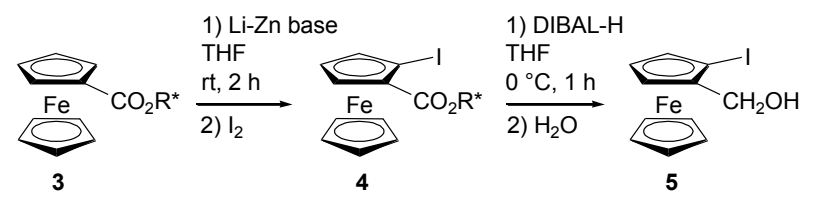

\begin{tabular}{cccc}
\hline Entry & $\mathbf{3}$ & $\mathbf{4}$, yield $(\%), \mathrm{de}^{a}(\%)$ & $\mathbf{5}$, yield $(\%), \mathrm{ee}^{b}(\%)$ \\
\hline 1 & $\mathbf{3 a}$ & $\mathbf{4 a}, 86,20$ & $61,22(R)^{c}$ \\
\hline 2 & $\mathbf{3 b}$ & $\mathbf{4 b}, 50^{d}, 17$ & $(S)^{c, e}$ \\
\hline 3 & $\mathbf{3 c}$ & $\mathbf{4 c}, 86,54$ & $(S)^{c, e}$ \\
\hline 4 & $\mathbf{3 d}$ & $\mathbf{4 d}, 87,56$ & $96,57(S)^{c}$ \\
\hline 5 & $\mathbf{3 e}$ & $\mathbf{4 e}, 64^{d}$ & $86,32(S)^{c}$ \\
\hline $6^{f}$ & $\mathbf{3 f}$ & $\mathbf{4 f}, 70$ & $91,11(S)^{c}$ \\
\hline $7^{g}$ & $\mathbf{3 g}$ & $\boldsymbol{R}_{\mathbf{P}}-\mathbf{4 g}, 35$ and $\boldsymbol{S}_{\mathbf{P}^{-}}-\mathbf{4 g}, 12^{d}$ & $81,96(R)$ and $88,92(S)^{c}$ \\
\hline
\end{tabular}

${ }_{5}{ }^{a}$ Wherever possible, determined from the integration of the ${ }^{1} \mathrm{H}$ NMR spectrum of the crude mixture. ${ }^{b}$ Determined by HPLC analysis on a chiral stationary phase (AS-H column, eluent: hexane/isopropanol 9:1, 1 $\mathrm{mL} / \mathrm{min}, \lambda=252 \mathrm{~nm}$ ). ${ }^{c}$ Absolute configuration assigned on the basis of reported data. ${ }^{8} d$ Estimated yield, due to the presence of starting

10 material. ${ }^{e}$ Reduction performed on a fraction. ${ }^{f}$ Using $\mathrm{ZnCl}_{2}$. TMEDA (1.5 equiv) and TMPLi ( 4.5 equiv). ${ }^{g}$ Both diastereomers separated by column chromatography purification over silica gel.

A thorough study was then undertaken in order to evaluate the parameters responsible for the diastereoselectivity observed from 15 promising $3 \mathbf{c}$ (Table 2). In order to check the importance of the structure composition of the base, (TMP) $)_{2} \mathrm{BuZnLi}^{6 \mathrm{~b}}$ was tested; similar yield and de were obtained (Table 2, entry 2). Using hexane containing TMEDA (5 equiv) ${ }^{9}$ instead of THF still led to $\mathbf{4 c}$ but in lower yield and de (Table 2, entry 3 ). The presence of ${ }_{20}$ TMEDA $^{10}$ in THF, due to the zinc source used, did not change the diastereoselectivity, as shown employing $\mathrm{ZnCl}_{2}$ instead of $\mathrm{ZnCl}_{2}$. TMEDA (Table 2, entries 4,5). The addition of TMPLi (1 or 2 equiv) to a mixture of (TMP) $)_{2} \mathrm{Zn}$ and $\mathbf{3 c}$ was attempted, and led to $87-89 \%$ yield, and 64 or $72 \%$ de, respectively (Table 2, 25 entries 6,7), as if TMPLi (or aggregates containing $\mathrm{LiCl}$ ) ${ }^{6 \mathrm{c}}$ was superior to mixed ferrocenyl-TMP zincates to perform the diastereoselective reaction. Similarly, the addition of TMPLi (3 equiv) to a mixture of $\mathrm{ZnCl}_{2}$. TMEDA and 3c led to an improved de (Table 2, entry 8 ). The sequential addition of (TMP) ${ }_{2} \mathrm{Zn}$ and 30 TMPLi ( 2 equiv) was also attempted using 1,2-dimethoxyethane, 1,4-dioxane, and dimethoxymethane as solvents, but the reaction only proceeded with the latter, affording $\mathbf{4 c}$ in $32 \%$ yield and $51 \%$ de (Table 2, entry 9). Mixing the reagents in different orders at -30 or $-50{ }^{\circ} \mathrm{C}$ before warming to $\mathrm{rt}$ did not change significantly 35 the diastereoselectivity (Table 2, entries 10-13).

Double asymmetric induction ${ }^{11}$ using commercial $(R)$ - and $(S)$ bis[1-phenylethyl]amine (PEAH) as ligand source instead of TMPH was next attempted. Thus, when the substrate was reacted with a base obtained from $\mathrm{ZnCl}_{2}$. TMEDA (1 equiv) and $(R)$ - or $40(S)$-PEALi (3 equiv), 4c was obtained in 67 and $24 \%$ yield, and 79 and $10 \%$ de, respectively (Table 2, entries 14-15). The sequential addition of the zinc diamide (1 equiv) and lithium amide ( 2 equiv) to the substrate being more efficient in the case of TMPH (Table 2, entry 7), we applied a similar protocol using 45 (R)-PEAH; under these conditions, both good yield and de were obtained (Table 2, entry 16).
Applied to the ester $\mathbf{3 g}$, the sequential addition of $(\mathrm{TMP})_{2} \mathrm{Zn}$ (either prepared from $\mathrm{ZnCl}_{2}$.TMEDA or $\mathrm{ZnCl}_{2}$ ) and TMPLi (2 equiv) afforded $\boldsymbol{R}_{\mathbf{P}} \mathbf{- 4 g}$ in 51 and $57 \%$ yield, respectively.

50 Table 2 Metallation of the chiral ferrocenecarboxylate $3 \mathbf{c}$ using the lithium-zinc base prepared from $\mathrm{ZnCl}_{2}$. TMEDA (1 equiv), $\mathrm{RLi}$ ( 2 equiv) and $\mathrm{R}$ ' $\mathrm{Li}$ ( $\mathrm{n}$ equiv) before trapping with $\mathrm{I}_{2}$ ( 3 equiv).

\begin{tabular}{|c|c|c|c|c|}
\hline & & $3 c$ & $\begin{array}{l}\text { 1) Li-Zn base } \\
\text { solvent, conditions }\end{array}$ & \\
\hline & & & 2) $I_{2}$ & \\
\hline Entry & $\mathrm{R}$ & $\mathrm{R}^{\prime}(\mathrm{n})$ & Solvent, conditions & Yield $(\%), \mathrm{de}^{a}(\%)$ \\
\hline 1 & TMP & TMP(1) & THF, rt, $2 \mathrm{~h}$ & $86,54\left(S^{b}\right)$ \\
\hline 2 & TMP & $\mathrm{Bu}(1)$ & THF, rt, $2 \mathrm{~h}$ & $89,55\left(S^{b}\right)$ \\
\hline 3 & TMP & $\mathrm{TMP}(1)$ & ${ }^{c}, \mathrm{rt}, 2 \mathrm{~h}$ & $50,42\left(S^{b}\right)$ \\
\hline $4^{d}$ & TMP & TMP(1) & THF, rt, $2 \mathrm{~h}$ & $84,56\left(S^{b}\right)$ \\
\hline $5^{d, e}$ & TMP & TMP(1) & $\mathrm{THF},-30{ }^{\circ} \mathrm{C}$ to rt, $2 \mathrm{~h}$ & $46,53\left(S^{b}\right)$ \\
\hline $6^{f}$ & TMP & $\mathrm{TMP}(1)$ & THF, rt, $2 \mathrm{~h}$ & $89,64\left(S^{b}\right)$ \\
\hline $7^{f}$ & TMP & $\mathrm{TMP}(2)$ & THF, rt, $2 \mathrm{~h}$ & $87,72\left(S^{b}\right)$ \\
\hline 8 & $g$ & TMP(3) & THF, $-30{ }^{\circ} \mathrm{C}$ to rt, $2 \mathrm{~h}$ & $70,68\left(S^{b}\right)$ \\
\hline $9^{d, f}$ & TMP & TMP(2) & ${ }^{h}, \mathrm{rt}, 2 \mathrm{~h}$ & $32,51\left(S^{b}\right)$ \\
\hline $10^{f}$ & TMP & $\operatorname{TMP}(2)$ & THF, $-30{ }^{\circ} \mathrm{C}$ to $\mathrm{rt}, 2 \mathrm{~h}$ & $51,52\left(S^{b}\right)$ \\
\hline 11 & TMP & $\mathrm{TMP}(2)$ & $\mathrm{THF},-30{ }^{\circ} \mathrm{C}$ to rt, $2 \mathrm{~h}$ & $64,56\left(S^{b}\right)$ \\
\hline $12^{d}$ & TMP & TMP (2) & $\mathrm{THF},{ }^{i}-30^{\circ} \mathrm{C}$ to rt, $2 \mathrm{~h}$ & $30,56\left(S^{b}\right)$ \\
\hline $13^{j}$ & TMP & TMP(2) & $\mathrm{THF},-50{ }^{\circ} \mathrm{C}$ to rt, $2 \mathrm{~h}$ & $71,56\left(S^{b}\right)$ \\
\hline 14 & $\mathrm{PEA}^{k}$ & $\operatorname{PEA}^{k}(1)$ & THF, rt, 2 h & $67,79\left(S^{b}\right)$ \\
\hline 15 & $\mathrm{PEA}^{l}$ & $\operatorname{PEA}^{l}(1)$ & THF, rt, $2 \mathrm{~h}$ & $24,10\left(S^{b}\right)$ \\
\hline $16^{f}$ & $\mathrm{PEA}^{k}$ & $\operatorname{PEA}^{k}(2)$ & THF, rt, $2 \mathrm{~h}$ & $85,91\left(S^{b}\right)$ \\
\hline
\end{tabular}

${ }^{a}$ Determined from the integration of the ${ }^{1} \mathrm{H}$ NMR spectrum of the crude 55 mixture. ${ }^{b}$ Determined after reduction using DIBAL-H by HPLC analysis on a chiral stationary phase (AS-H column, eluent: hexane/isopropanol 9:1, $1 \mathrm{~mL} / \mathrm{min}, \lambda=252 \mathrm{~nm}$ ). ${ }^{c}$ In hexane containing TMEDA (5 equiv). ${ }^{d}$ Base prepared from $\mathrm{ZnCl}_{2}$ instead of $\mathrm{ZnCl}_{2}$. TMEDA. ${ }^{e}$ TMEDA slowly added at $-30{ }^{\circ} \mathrm{C} .{ }^{f}$ Sequential addition 60 of RLi and, 10 min later, R'Li. ${ }^{g}$ Substrate mixed with $\mathrm{ZnCl}_{2}$. TMEDA before reaction (no RLi used). ${ }^{h}$ Using dimethoxymethane as solvent. ${ }^{i}$ Containing TMEDA (1 equiv). ${ }^{j}$ Base transferred to the substrate. ${ }^{k}$ Using $(R)$-PEAH. ${ }^{l}$ Using $(S)$-PEAH.

In order to access the quinolinones $\mathbf{1}$, the iodides $S_{\mathbf{P}^{-}} \mathbf{4} \mathbf{c}$ and ${ }_{65} \boldsymbol{R}_{\mathbf{P}} \mathbf{- 4 g}$ were reacted with 2-aminophenylboronic acid. Using catalytic $\mathrm{Pd}(\mathrm{dba})_{2} \quad(\mathrm{dba}=$ dibenzylidene acetone $)$ and triphenylphosphine, dioxane as solvent, and $\mathrm{CsF}$ in order to avoid the use of basic reagents, ${ }^{12}$ led to the carboxamides $\boldsymbol{R}_{\mathbf{P}} \mathbf{- 1}$ and $\boldsymbol{S}_{\mathbf{P}} \mathbf{- 1}$ through Suzuki cross-coupling and subsequent cyclization of the 70 amino group with the ester function (Scheme 3).

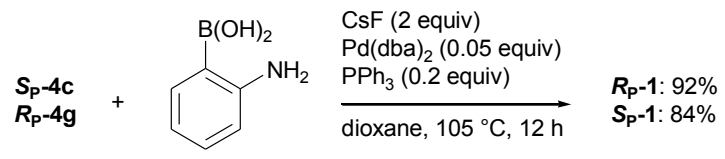

Scheme 3 Cyclizing Suzuki couplings giving 1.

Crystals were analysed by X-ray diffraction and a structure referring to the non-chiral space group R-3 was obtained (Figure 75 1). This result is not sufficient to claim racemization, ${ }^{13}$ but led us to check this possibility using HPLC on chiral phases. The interconversion $\left(\boldsymbol{R}_{\mathbf{P}}-\mathbf{1}\right.$ vs $\boldsymbol{S}_{\mathbf{P}}$-1) was noted in solution; ${ }^{14}$ without solvent, it could be stopped at temperatures below $-20{ }^{\circ} \mathrm{C}$. 

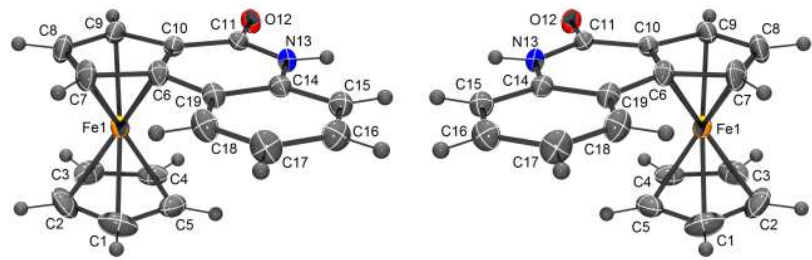

Figure 1 ORTEP diagrams (30\% probability) of $\boldsymbol{R}_{\mathbf{P}}-\mathbf{1}$ and $\boldsymbol{S}_{\mathrm{P}} \mathbf{- 1}$.

Lithiation experiments on aryl carboxamides showed that the orientation of the function has an impact on the efficiency of the 5 ortho-metallations, which increases with the coplanarity of the oxygen and activated hydrogen with the ring. ${ }^{15}$ A rationalization of the diastereoselectivity observed using $\mathbf{3 c}$ was thus attempted by identifying more stable conformers. The geometrical (local stabilization) optimization was performed by changing the 10 dihedral angle between the upper plane of the ferrocenyl moiety and the ester carbonyl group (B3LYP/6-31G(d), structure of the ferrocenyl group fixed). The dihedral angle was fixed with $30^{\circ}$ intervals from $0^{\circ}$ to $330^{\circ}$. Two most stable structures, with dihedral angles of $0^{\circ}$ (to give the major diastereomer) and $180^{\circ}$ 15 (to give the minor diastereomer), were identified and calculated in greater detail $(\mathrm{M} 06 / \mathrm{LanL} 2 \mathrm{DZ}(\mathrm{Fe}) \& 6-31 \mathrm{G}(\mathrm{d}))$ at around $0^{\circ}$ and $180^{\circ}$. The conformation with the dihedral angle of $-6^{\circ}$ proved 4.6 kcal.mol ${ }^{-1}$ lower in energy that of $190^{\circ}$ (Figure 2, left). ${ }^{16}$ These calculated results are in accordance with the observed 20 diastereoselectivity in the deproto-metallation of $\mathbf{3 c}$ using the lithium-zinc combination (Scheme 4). It is interesting to note that the structure obtained by X-ray diffraction of suitable crystals of 3c corresponds to the most stable conformer (Figure 2, right).

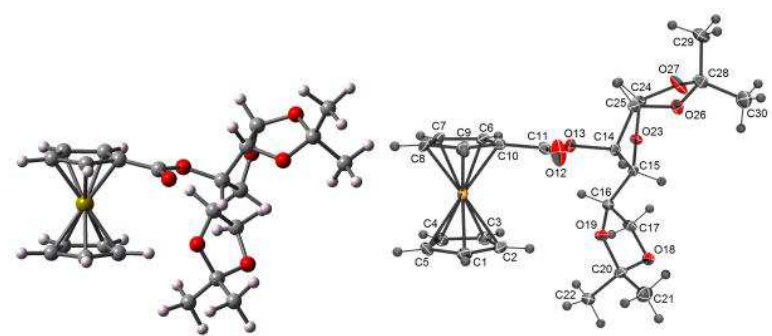

25 Figure 2 Calculated most stable conformer (M06/LanL2DZ(Fe)\&6$31 \mathrm{G}(\mathrm{d}))$ and ORTEP diagram (30\% probability) of $\mathbf{3 c}$.
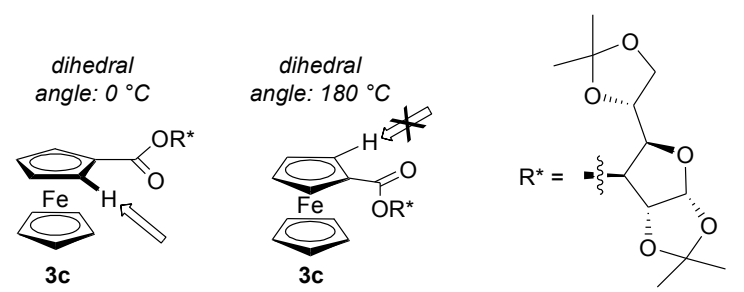

Scheme 4 Observed diastereoselectivity in the deproto-metallation of 3c.

\section{Conclusions}

30 Sugar-based ferrocene esters were deproto-metallated by using mixed lithium-zinc amido-based bases, with diastereoselectivities up to $91 \%$ under the 'double asymmetric induction' protocol.

The authors gratefully acknowledge Institut Universitaire de France, Région Bretagne (financial support to A.S. and G.D.), ${ }_{35}$ University of Rennes 1 and CNRS (financial support to G.D. and D.V.R.). This research has also been performed as part of the
Indo-French "Joint Laboratory for Sustainable Chemistry at Interfaces". The calculations were performed by using the RIKEN Integrated Cluster of Clusters (RICC) facility.

\section{${ }_{40}$ Notes and references}

${ }^{a}$ Chimie et Photonique Moléculaires, UMR 6226 Institut des Sciences Chimiques de Rennes, CNRS-Université de Rennes 1, Bâtiment 10A, Case 1003, Campus Scientifique de Beaulieu, 35042 Rennes, France. E-mail: florence.mongin@univ-rennes1.fr; Fax: +33-2-2323-6955.

$45^{b}$ D-211, Discovery Laboratory, Organic and Biomolecular Chemistry Division, CSIR-Indian Institute of Chemical Technology, Hyderabad500607, India.E-mail: prkgenius@iict.res.in; Fax: +91-40-27160387. ${ }^{c}$ Centre de Diffractométrie X, UMR 6226 Institut des Sciences Chimiques de Rennes, CNRS-Université de Rennes 1, Bâtiment 10B, Campus 50 Scientifique de Beaulieu, 35042 Rennes, France.

${ }^{d}$ Graduate School of Pharmaceutical Sciences, The University of Tokyo,

7-3-1 Hongo, Bunkyo-ku, Tokyo 113-0033, Japan.

E-mail: uchiyama@mol.f.u-tokyo.ac.jp

${ }^{e}$ Advanced Elements Chemistry Research Team, RIKEN-ASI, 2-1

55 Hirosawa, Wako-shi, Saitama 351-0198, Japan.

$\dagger$ Electronic Supplementary Information (ESI) available: procedures, Xray diffraction analysis and CIF files of $\mathbf{1}$ (CCDC 872139) and 3c (CCDC 798863), NMR spectra of 1, geometrical optimization of $\mathbf{3 c}$ and computational details. See DOI: 10.1039/b000000x/

601 N. J. Long, Angew. Chem. Int. Ed. Engl., 1995, 34, 21-38.

2 D. R. van Staveren and N. Metzler-Nolte, Chem. Rev., 2004, 104, 5931-5985.

3 (a) A. Togni and T. Hayashi, Ferrocene, VCH Verlagsgesellshaft, Weinheim, 1995; (b) R. C. J. Atkinson, V. C. Gibson and N. J. Long,

65 Chem. Soc. Rev., 2004, 33, 313-328; (c) W.-P. Deng, V. Snieckus and C. Metallinos, Chiral Ferrocenes in Asymmetric Catalysis: Synthesis and Applications, Wiley-VCH, Weinheim, 2010.

4 (a) A. Sreeshailam, G. Dayaker, F. Chevallier, T. Roisnel, P. Radha Krishna and F. Mongin, Eur. J. Org. Chem., 2011, 3715-3718; (b) G.

70 Dayaker, A. Sreeshailam, F. Chevallier, T. Roisnel, P. Radha Krishna and F. Mongin, Chem. Commun., 2010, 46, 2862-2864.

5 A. Rauf and H. Parveen, Eur. J. Lipid Sci. Technol., 2004, 106, $97-$ 100.

6 (a) J. M. L'Helgoual'ch, A. Seggio, F. Chevallier, M. Yonehara, E.

75 Jeanneau, M. Uchiyama and F. Mongin, J. Org. Chem., 2008, 73, 177-183; (b) K. Snégaroff, S. Komagawa, F. Chevallier, P. C. Gros, S. Golhen, T. Roisnel, M. Uchiyama and F. Mongin, Chem. Eur. J., 2010, 16, 8191-8201; (c) P. García-Álvarez, R. E. Mulvey and J. A. Parkinson, Angew. Chem. Int. Ed., 2011, 50, 9668-9671.

807 T. Pickett, E., F. Roca, X. and C. Richards, J., J. Org. Chem., 2003, 68, 2592-2599.

8 A. Patti, D. Lambusta, M. Piattelli and G. Nicolosi, Tetrahedron: Asymmetry, 1998, 9, 3073-3080.

9 A. Seggio, M.-I. Lannou, F. Chevallier, D. Nobuto, M. Uchiyama, S.

85 Golhen, T. Roisnel and F. Mongin, Chem. Eur. J., 2007, 13, 9982 9989.

10 R. R. Fraser and T. S. Mansour, Tetrahedron Lett., 1986, 27, 331334.

11 C. Metallinos and V. Snieckus, Org. Lett., 2002, 4, 1935-1938.

9012 S. W. Wright, D. L. Hageman and L. D. McClure, J. Org. Chem. 1994, 59, 6095-6097.

13 J.-P. Djukic, A. Hijazi, H. D. Flack and G. Bernardinelli, Chem. Soc. Rev., 2008, 37, 406-425.

14 Concerning previously reported $\mathrm{rt}$ racemization of ferrocenes, see for

95 example: M. Tsukazaki, M. Tinkl, A. Roglans, B. J. Chapell, N. J. Taylor and V. Snieckus, J. Am. Chem. Soc., 1996, 118, 685-686.

15 (a) P. Beak and A. I. Meyers, Acc. Chem. Res., 1986, 19, 356-363; (b) P. Beak, S. T. Kerrick and D. J. Gallagher, J. Am. Chem. Soc., 1993, 115, 10628-10636; (c) M. C. Whisler, S. MacNeil, V. Snieckus and P. Beak, Angew. Chem. Int. Ed., 2004, 43, 2206-2225.

16 The calculations using the SCRF method (PCM, solvent $=$ THF) gave similar results. For details, see ESI. ${ }^{\dagger}$ 
Graphical and textual abstract for the contents pages.

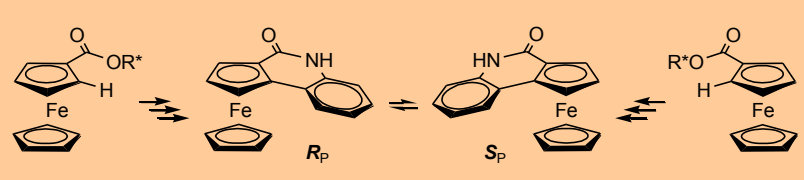

$5\left(R_{\mathrm{P}}\right)$ - and $\left(S_{\mathrm{P}}\right)$-ferrocene[1,2-c]1H-quinolin-2-one were synthesized from sugar-derived ferrocene esters using diastereoselective deprotometallation by lithium-zinc combinations followed by iodination and cyclizing coupling.

4 